\title{
Another look at the water phases that exist under room conditions
}

\author{
T.A. Yakhno ${ }^{1}$, V.G. $9 \times \mathrm{xHO}^{1,2}$. \\ ${ }^{1}$ Federal Research Center Institute of Applied Physics of the Russian Academy of Sciences (IAP RAS), \\ Nizhny Novgorod 603950, Russia \\ ${ }^{2}$ N. I. Lobachevsky State University of Nizhny Novgorod (National Research University), Nizhny Novgorod 603950, \\ Russia \\ * Correspondence: yakhta13@gmail.com (T.Y.); yakhno@appl.sci-nnov.ru (V.Y.); \\ Tel.: (011)-7-831-436-85-80 (T.Y. \& V.Y.)
}

\begin{abstract}
A brief review of the history of the problem is intended to trace the progress in the development of scientific views on the structure of water. The discoveries in this area made in the first half of the last century are considered in comparison with modern data. It is shown that due to the de facto ban on the study of the structure of water in 1971, work in this direction was frozen for a long time. The paradox is that many forgotten truths have been independently "rediscovered" in our time, which speaks of their authenticity. On the basis of scientific literature and their own research, the authors come to the conclusion that water under room conditions is a microdispersed system, one phase of which is represented by continuous water, and the other - by polywater, discovered in the 70 s of the last century.
\end{abstract}

Key words: phases of water; microstructure, dispersion, physical and chemical properties, polywater.

From the standpoint of world academic science, water at room temperature and humidity is still an association of $\mathrm{H} 2 \mathrm{O}$ molecules, molecular chains and nanometer-sized clusters dynamically changing their structure in femtosecond time [1, 2]. By introducing certain assumptions, the authors of such views were able to explain certain anomalous properties of water and ice with the help of molecular modeling. At the same time, information about the presence of other phases of water coexisting with the continuum one was not taken into account.

Meanwhile, more than 70 years ago (see review [3]), convincing experimental facts were obtained that indicate that water near hydrophilic surfaces forms a new phase - a nearsurface layer, which is very different in terms of the complex of physical properties from bulk water. The thickness of this layer is up to hundreds of microns. Direct evidence of the existence of a new water phase was presented, including in terms of refractive index, diffraction of X-ray and neutron radiation, viscosity, adhesion, and the presence of long-range order in structural ordering. This information has been repeatedly confirmed by many researchers using different techniques of physical experiments. Experimental evidence was obtained for the fact that the structure of water formed at hydrophilic surfaces corresponds to the structure of ice and represents layers of hexagonal structures superimposed on each other in one, two, three or four layers [4-7]. It has been shown that thin $(\mathrm{h}<150 \mu \mathrm{m})$ layers of water located between glass surfaces have shape elasticity [8]. Films with a thickness of $0.35 \mu \mathrm{m}$ had the rigidity of metallic lead [9]. The viscosity of water in the gap between glass plates separated by $1 \mu \mathrm{m}$ was many times higher than the viscosity of water in the volume [10], and at a distance between the plates of $2.5 \mu \mathrm{m}$ it was 10 times higher [11].

The data on the existence of a new phase of water under room conditions were not accepted by representatives of "classical science". Suffice it to recall the opening and closing of 
"polivoda" (water-II) [12-14]. The water obtained by Soviet scientists during the condensation of water vapor in ultra-thin quartz capillaries had a significantly higher viscosity, density, refractive index, and surface tension than ordinary water. Its dissolving power was less. Experiments on obtaining polywater have been successfully reproduced in many research laboratories around the world, including Europe, the USA and Australia, and were widely discussed in the press and at international forums $[15,16]$. The molecular weight of water-II determined from the vapor density exceeded this indicator for ordinary water by 8-10 times, and the absorption in the IR region was characterized by two peaks that are not characteristic of any other known substance [17]. Based on the data obtained, it was assumed that the new substance is a polymer consisting of water molecules combined into hexagonal cells (Fig. 1) [17]. Upon the formation of water-II from ordinary water vapor on the surface of fused quartz or glass B.V. Deryagin assumed the existence of a special kind of condensation catalysis [16]. However, in water samples in a number of laboratories, inorganic [18-20] and organic [16] impurities were found. In addition, unique IR absorption bands characteristic of polywater (1595 $\mathrm{cm}^{-1}$ and $1400 \mathrm{~cm}^{-1}$ ) were also found in a sample of human sweat [21]. All this, ultimately, served as a reason for accusing the authors of the discovery of insufficient purity of the experiment and called into question the very existence of the phenomenon [22]. At the same time, for example, the hypothesis about the possible existence of polywater in biological fluids was ignored.

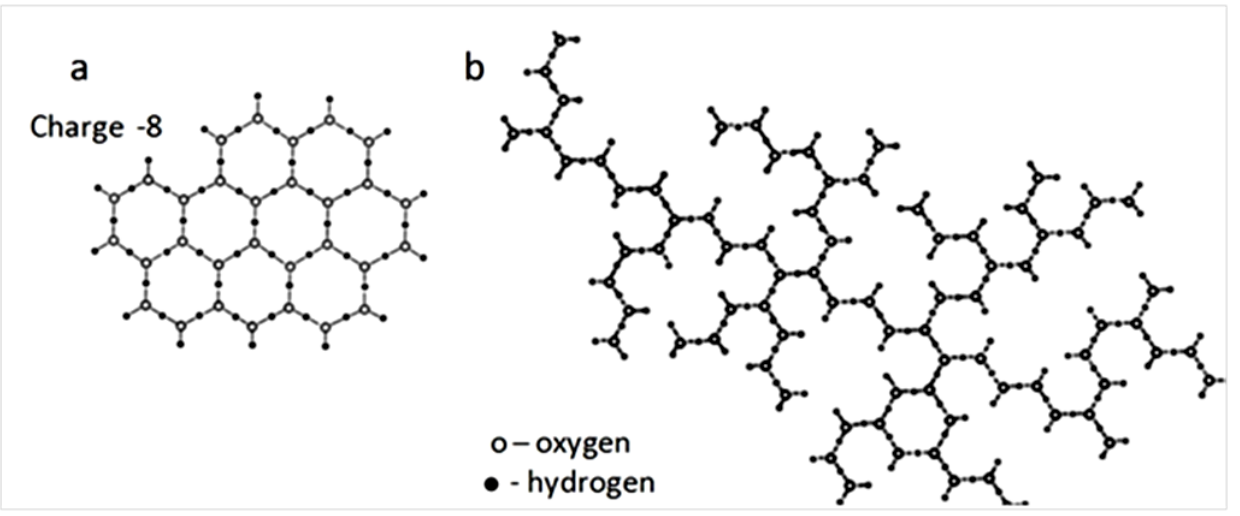

Figure 1. Representation of the authors [17] about the molecular structure of polywater: a structural diagram of polywater, consisting of a network of hexagonal blocks; $b$ - monolayer.

Under the onslaught of skeptical colleagues, the authors were forced to publicly "repent" [23,24]. However, it turned out that the "impurities", interacting with the surrounding water, significantly change its properties at the interface. In the work [25, p. 68] we read: " $A$ new stage in the study of surface phenomena was the discovery of a special structure of layers of polar liquids, bordering with the surface of an adjacent phase. Under the influence of this surface, polar molecules are oriented relative to it in a certain way, and this orientation is transferred from layer to layer over a certain distance. A similar phenomenon was observed for the first time in water layers adjacent to the surface of a hydrophilic body. In this case, the degree of orientation decreases with distance from the substrate, becoming insignificant at a distance of the order of the length of hundreds of molecules. As a result of a change in the structure, the properties of the boundary layers of water (refractive index, density, viscosity, 
dissolving ability) differ from the normal ones characteristic of the volume of water. The freezing point also changes. It is for this reason, as we have shown, that in permafrost regions the layers of water adjacent to the particles of hydrophilic clays do not freeze, at least at temperatures not lower than $-10^{\circ} \mathrm{C}$. "And further (p. 70): "According to its optical properties, the boundary layer is homogeneous and anisotropic, like liquid crystals, and is separated from the bulk phase by a sharp interface. Thus, in addition to the previously known solid, liquid and gaseous phases, there are "boundary phases" of a strictly defined thickness, which naturally decreases with increasing temperature. "

After the "exposure" of the researchers of the new phase of water, the work in this direction was frozen and partially forgotten. However, after half a century, the opinion that liquid water is two-phase resurfaced. According to modern data, the simplest model of the structure of liquid water assumes the existence of two separate microscopic phases [26-31]. Many physical quantities exhibit behavior that suggests the presence of two states in liquid water. For example, infrared and Raman spectra, as well as the presence of an isobestic point in the Raman spectra, are considered as a clear sign confirming the model of a mixture of two phases [31]. According to Preparata et all [32], liquid water is a two-component liquid system consisting of a coherent phase (about $40 \%$ of the total volume at room temperature) and an incoherent phase. Thin films of water of ice-like structure with a thickness of several molecular layers on hydrophilic surfaces have been rediscovered [33-37]. Obviously, these water films are formed from water vapor present in the ambient air, since their thickness depends on humidity.

At this nanoscale level, interfacial water near hydrophilic surfaces exhibits a viscosity of about 2 to $10^{6}$ times that of bulk water, while no significant changes in the viscosity of water near hydrophobic surfaces are observed [38]. When a hydrophilic surface is immersed in water, a layer of structured liquid crystalline water up to $500 \mu \mathrm{m}$ thick forms near it in a few minutes, displacing ions and microparticles from it, which are usually present in an aqueous medium [39, 40]. An exclusion zone (EZ) is formed, due to which the concentration of ions and particles in free water increases, increasing also its osmotic pressure [41]. It is believed that the thin ice-like layer that covered the previously dry surface is used as a matrix for EZ growth [42-44].

Molecular dynamics has shown that water / solid and water / air interfaces strongly affect the structure and intermolecular dynamics of sessile water droplets, and suggests that intermolecular dynamics in other systems with interfaces differs from that in liquid water [45]. Interfacial water EZ is much more viscous than bulk water [46].

Despite the abundance of experimental evidence for the existence of the near-wall phase of water, a number of researchers stubbornly continue to deny this fact [47-51]. Several alternative explanations for EZ have been presented, in particular, Schurr's theory based on chemotaxis and diffusionophoresis [47]. This theory was strongly supported by Elton et al [48] and Esplandiu et al [49]. Another view of the formation of EZ is associated with swelling in water and partial destruction of Nafion, a solid polymer electrolyte, a popular owner of hydrophilic surfaces $[50,51]$. When this polymer swells, its fibers partially untwist and go out into bulk water. Such elongated strands can also form a rigid, parallel palisade that can repel colloidal microparticles; this, according to the authors of [51], creates the effect of an exclusion zone near Nafion. Analysis of alternative opinions is beyond the scope of this work. Pollack clearly commented on skeptical statements about the formation of a special near wall layer of 
water: "In sum, the four issues of challenge fail to derail the original line of interpretation, that the $E Z$ is a distinct, ordered structure that excludes solutes. Ample evidence for this interpretation (which Schurr seems to have missed) lends strength to this view "[52]. Further, we present works that, in our opinion, clearly indicate the existence of an additional phase in liquid water.

Two decades ago, sensational information appeared that liquid water is a heterogeneous polydisperse system [53-58]. To detect this fact, the following methods were used: visualization using laser radiation, which makes it possible to capture an insignificant difference in the refractive indices of two phases of water [53, 54]; laser modulationinterference phase microscopy and scattering of laser radiation in aqueous media purified from solid impurities [55]; static and dynamic small-angle light scattering [56]; method of small scattering angles in bidistilled water [58]. Measurements showed the presence in water of a spectrum of clusters in the range of 1.5 - 6.0 microns, as well as giant clusters tens and hundreds of microns in size. In Figure 2 shows a microphoto of ultrapure water preparations (OST 34-70- 953.2-88, specific conductivity 0.04-0.05 $\mu \mathrm{S} / \mathrm{cm}, \mathrm{pH}$ 5.4-7.0), distilled water (TU 2384-009-48326337-2015, specific 84 electrical conductivity $4.5 \mu \mathrm{S} / \mathrm{cm}, \mathrm{pH} 7.0$ ) and mineral water "Seraphim Dar" (mineralization 0.05-0.12 g / I). The thickness of the liquid layer in the preparations is $8 \mu \mathrm{m}$, the width of each frame is $3 \mathrm{~mm}$.
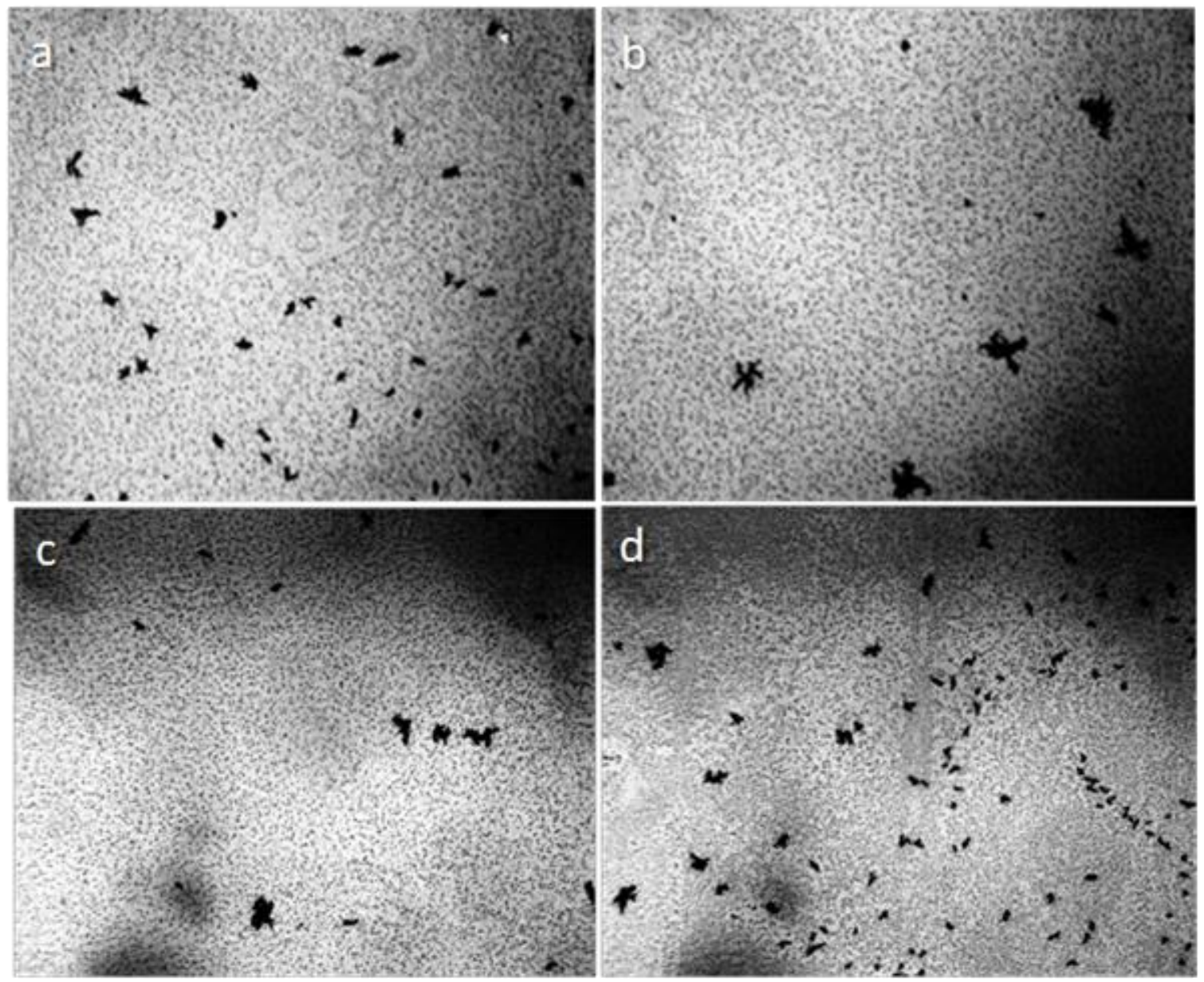
Figure 2. The structure of ultrapure water $(a, b)$ immediately after depressurization of the container is also a microdispersion and fundamentally corresponds to the structure of distilled (c) and mineral (d) water. The width of each frame is $3 \mathrm{~mm}$ [59].

The fact that water is a polydisperse system can be verified by observing under a microscope a drop suspended in a micro-hole $0.5 \mathrm{~mm}$ in diameter made in a plastic substrate (Figure 3).
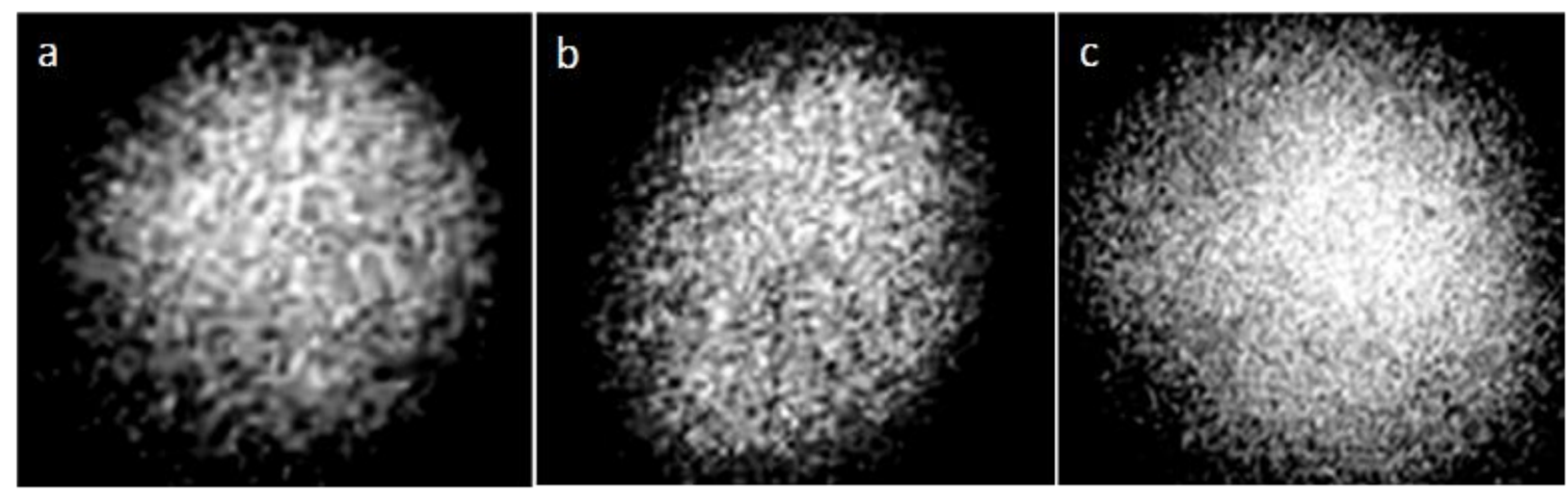

Figure 3. Microstructure of liquids in the "hanging drop" preparation. Liquid placed in a hole in a plastic plate with a diameter of $0.5 \mathrm{~mm}$. Microscopy "through liquid": a - distilled water; b tap water; c - water of the Black Sea [59].

After evaporation of equal volumes of water samples presented in Fig. 3, it turned out that the mass of the solid sediment corresponds to the proportion $\mathrm{a}: \mathrm{b}: \mathrm{c}=0.2: 0.45: 2.5$. In other words, the degree of dispersion of water in the volume turned out to be inversely proportional to the mass of substances dissolved in it. The fact that the dispersed phase of water is not an optical illusion can also be seen by examining the layer of water between the slide and the cover glass during the evaporation of the liquid phase (Figures 4, 5).

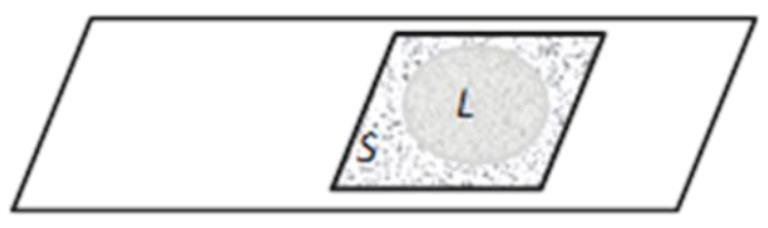

Figure 4. The "crushed drop" preparation is a thin layer of liquid between the slide and the cover glass during the evaporation of the liquid phase of water through the slits between the glasses. Evaporating through the edges of the preparation, the liquid recedes to the center, leaving a solid sediment on its way (Fig. 5): L - Liquid phase, S - Solid sediment. 

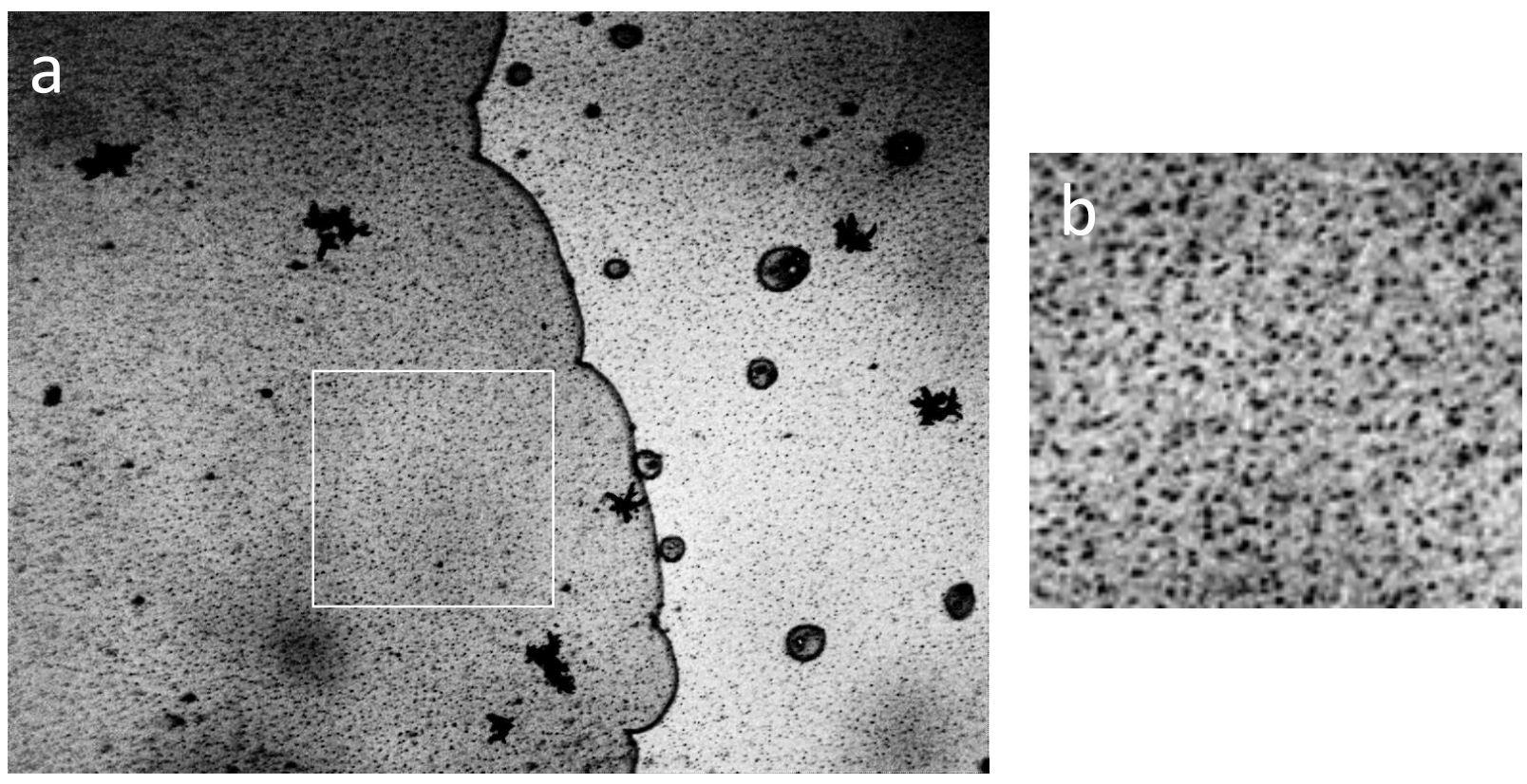

Figure 5. Microphoto of a part of the "crushed drop" preparation (Fig. 4) in the process of evaporation of the liquid phase. Fragment a: on the right (light part) - an evaporating liquid; on the left (dark part) the dispersed phase of water settling on a substrate; $b$ - fragment $a$, limited by a light square, at higher magnification. Frame width "a" is $3 \mathrm{~mm}[60]$.

In smears prepared from water and aqueous solutions, the dispersed phase is visible in the form of aggregates (Figure 6) [61].
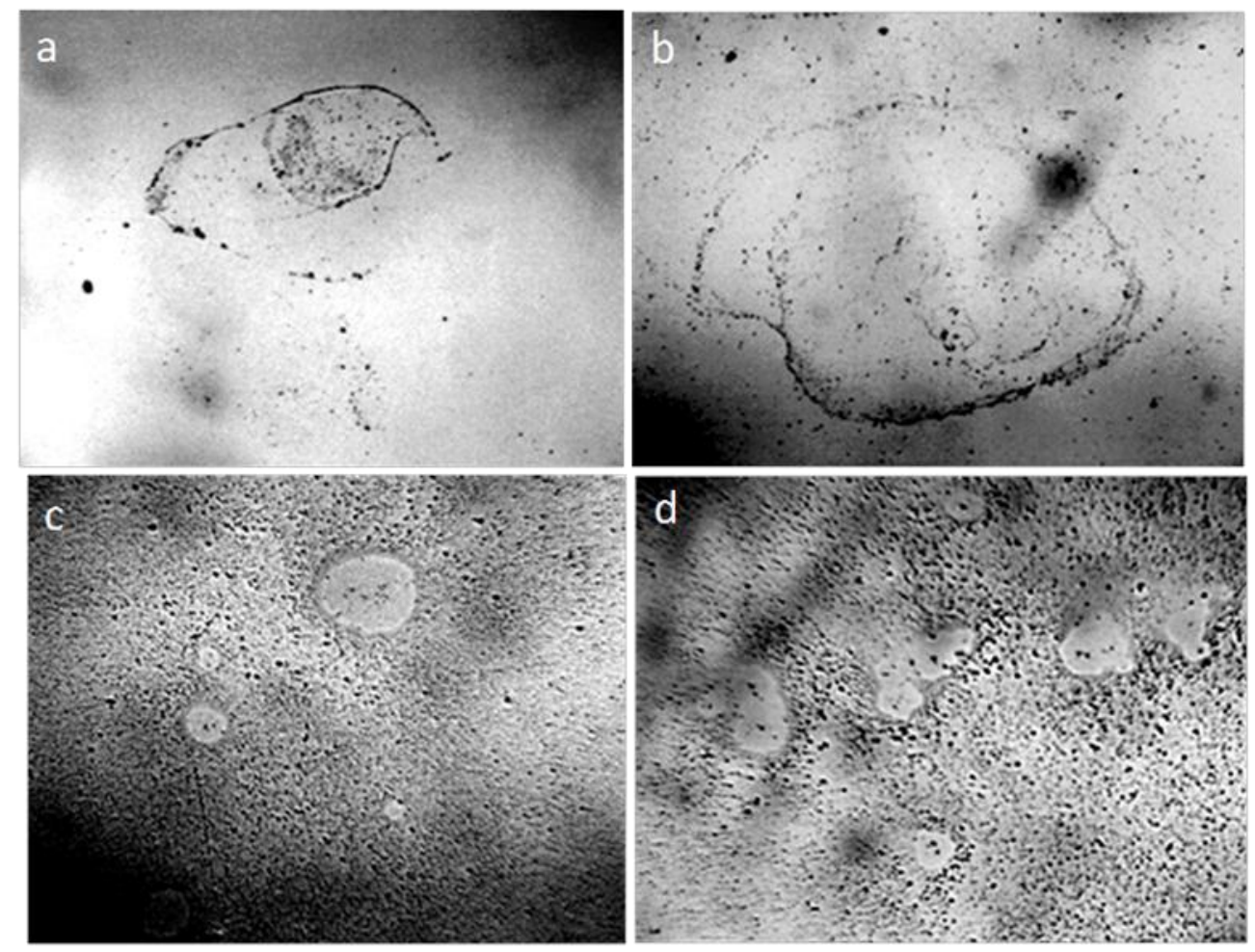

Figurure 6. Aggregates of the dispersed phase in dried smears: a- distilled water; b - dry white wine; c, $d$ - water solution of "Nescafe Gold" freeze-dried coffee. Microphoto. The width of each frame is $3 \mathrm{~mm}[61]$. 
In Figure 7 clearly visible aggregates of the dispersed phase of water in a thin layer of an aqueous solution of freeze-dried coffee "Nescafe Gold" (250 mg / $100 \mathrm{ml}$ ).
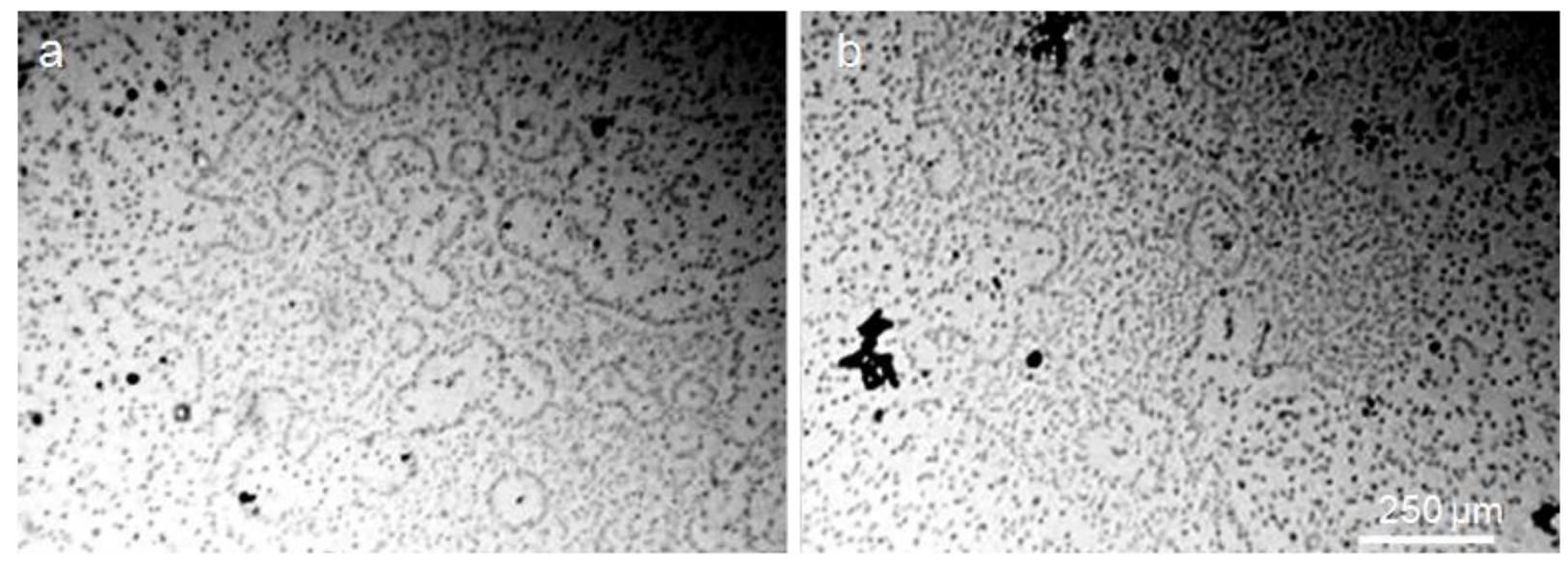

Figure 7. A layer of coffee solution between the slide and the cover slip is $8 \mu \mathrm{m}$ thick. Aggregates of the dispersed phase are visible.

Below is a diagram of the proposed organization of the structural unit of the micro-aggregate of the dispersed phase (Figure 8).

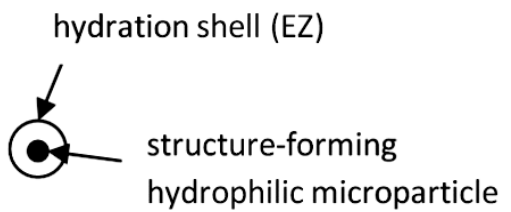

Figure 8. Scheme of the proposed organization of the structural unit of the microaggregate of the dispersed phase.

It is obvious that individual microaggregates can be combined into larger formations. Earlier, we put forward a hypothesis, which received experimental confirmation that the basis of the dispersed phase of water are microcrystals of $\mathrm{NaCl}$ salt, surrounded by a thick liquid crystal shell of hydrated water $[60,62]$. The evolution of water sediments drying in the open air has been traced $[62,63]$. It was shown that the aggregates do not evaporate at room temperature, exhibit the properties of a viscous liquid, do not dissolve in organic solvents (ether, hexane), but break down in strong salt solutions (Figure 9). 

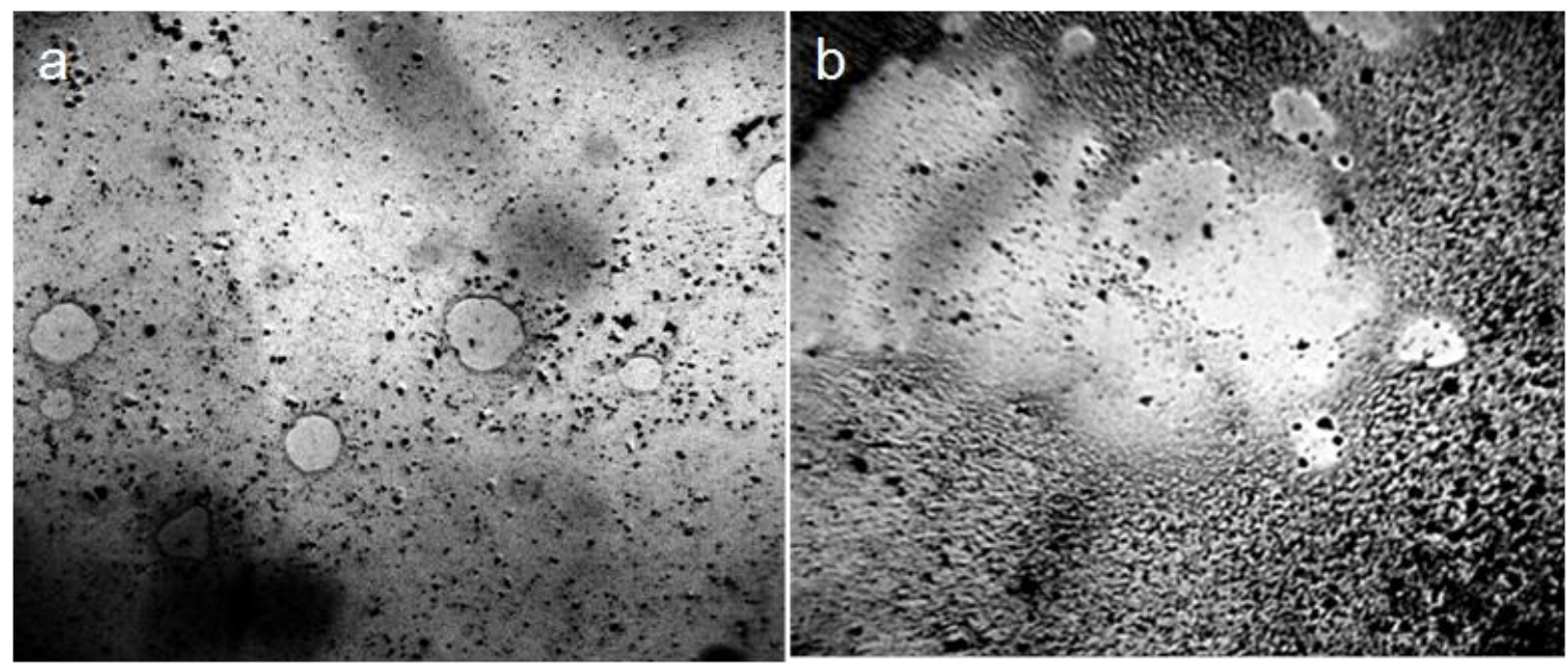

Figure 9. Dried sediment of coffee solution: a - after two hours of extraction with hexane, the dispersed phase aggregates retain their integrity; $b$ - after adding $\mathrm{NaCl}$ to the coffee solution at a dose of $4.0 \mathrm{~g} / 100 \mathrm{ml}$, the dispersed phase aggregates are destroyed.

The fact that an increase in $\mathrm{NaCl}$ concentration destroys the $\mathrm{EZ}$ structure was also reported by the authors of publications [64-66]. This fact confirms the common nature of the dispersed phase of water and EZ.

According to the results of gas chromatography-mass spectrometric analysis of a sample of dried coffee for water content, in the temperature range of $200-300^{\circ} \mathrm{C}$, the amount of water released from the analyzed sample increases abruptly, which may be associated with the destruction of its polymer structure [67] (Figure 10, Table 1.).

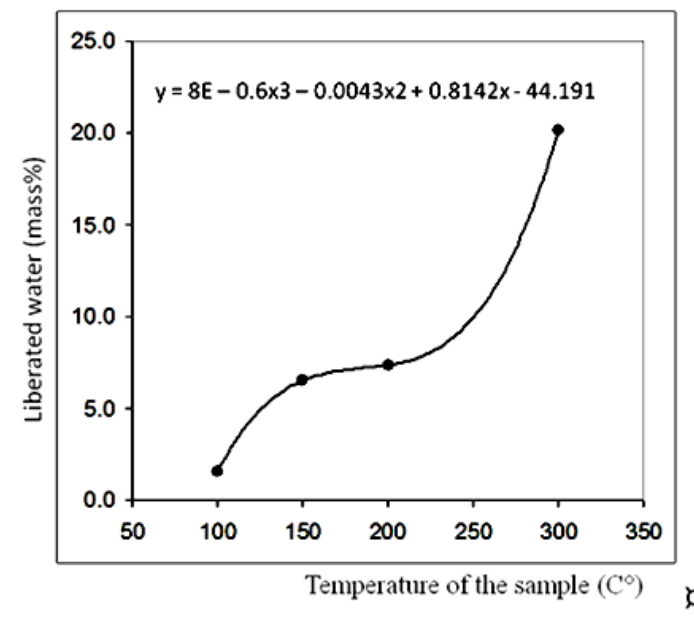

Table 1. Dependence $\cdot$ of $\cdot$ the $\cdot$ mass.fraction $\cdot$ of $\cdot$ released.water. on the temperature-of thermal-desorption ก

\begin{tabular}{|r|r|r|r|r|}
\hline № & $\begin{array}{c}\text { Thermal } \\
\text { desorption } \\
\text { temperature }\end{array}$ & $\begin{array}{c}\text { Sample } \\
\text { weight (m) }\end{array}$ & $\mathrm{S}\left(\mathrm{H}_{2} \mathrm{O}\right)$ & $\begin{array}{c}\text { w(H2O), } \\
\%\end{array}$ \\
\hline 1 & 100 & 7.2 & 4921843 & 1.6 \\
\hline 2 & 150 & 11.7 & 33178809 & 6.5 \\
\hline 3 & 200 & 10.6 & 33876750 & 7.4 \\
\hline 4 & 300 & 11.2 & 97991324 & 20.1 \\
\hline
\end{tabular}

Figure 10. Results of gas chromatography-mass spectrometric analysis of a sample of dried coffee for water content. A sharp increase in water evaporation occurs in the range of $200-300$ ${ }^{\circ} \mathrm{C}$, which may be associated with the destruction of the polymer structure of hydrated water.

To determine the relative density of dispersed phase aggregates, we centrifuged a Nescafe Gold coffee solution ( $250 \mathrm{mg} / 100 \mathrm{ml}$ of water) for $20 \mathrm{~min}$ at 1.5 thousand rpm and prepared 
smears from the upper, middle, and lower parts of the centrifugate. The results are shown in Fig. 11.
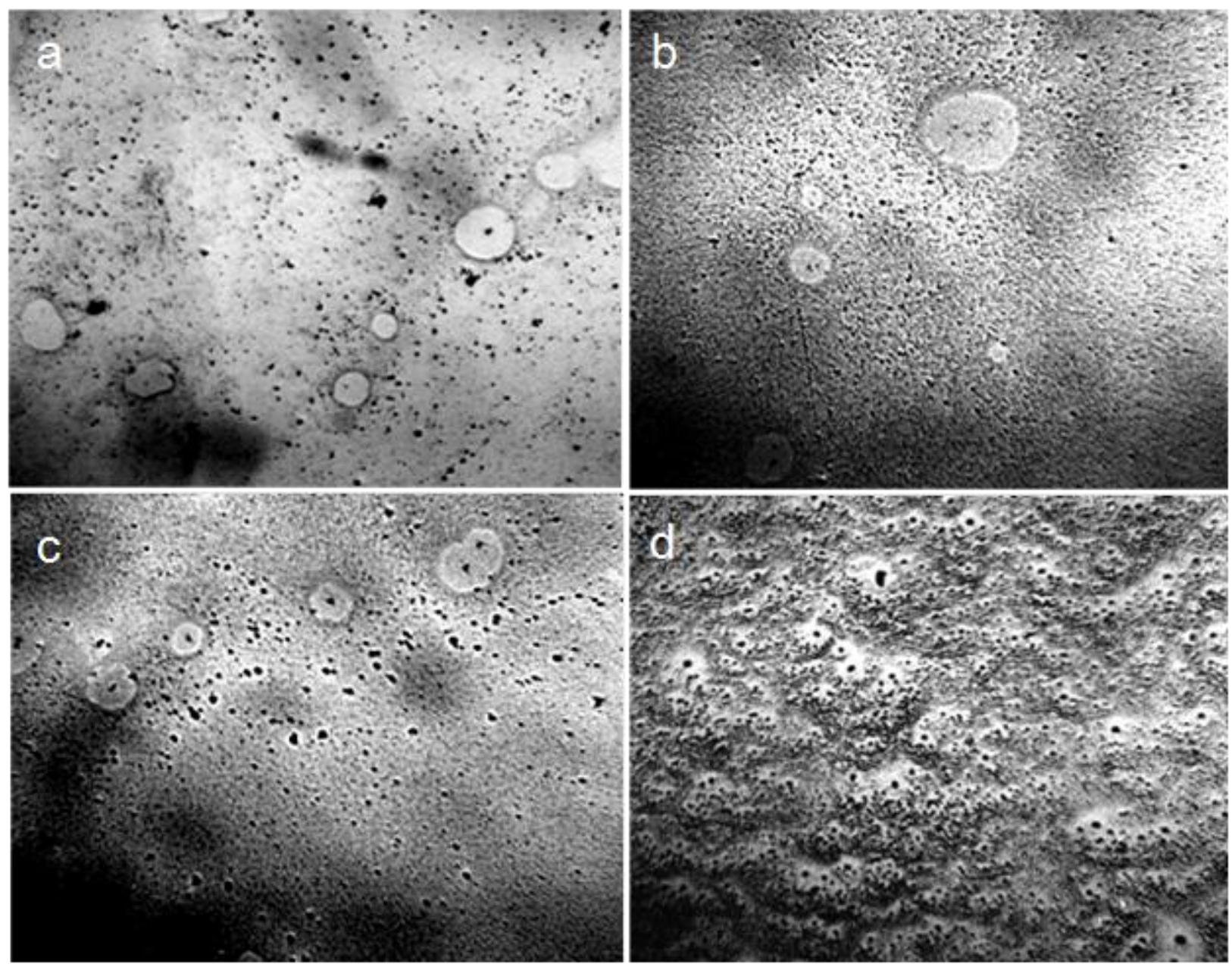

Figure 11. Microphoto of smears of Nescafe Gold coffee ( $250 \mathrm{mg} / 100 \mathrm{ml}$ of water), before and after centrifugation for $20 \mathrm{~min}$ at 1.5 thousand rpm. Samples were taken before centrifugation (a) and after, from different heights of the centrifuge tube: $b$ - from the upper part, c - from the middle part, $d$ - from the lower part. Frame width - $3 \mathrm{~mm}$.

Most of the complete aggregates were contained in the upper and middle parts of the tube. From this fact, it can be concluded that the dispersed phase is close in density to continuous water. More accurate measurements are needed.

The authors of [68] reported the discovery of isolated stable water clusters ranging in size from tens of nanometers to microns as a result of the evaporation of a highly dilute sodium chloride solution $\left(10^{-7} \mathrm{M}\right)$ at room temperature and normal atmospheric pressure. Stable water clusters are electrically charged (from $1.257 \mathrm{~V}$ to $-0.246 \mathrm{~V}$ ), as shown by studies using an electric force microscope. Raman scattering and infrared spectra of sediments show similar but not identical characteristics to liquid water. We will return to this information later. A review of modern works on the existence of isolated stable water clusters was made by Ho [69]. In studies [70,71], water structures are described, some of which, according to the authors' assumption, are accumulations of gas microbubbles. The above facts leave no doubt that water is a polydisperse system. According to Borilo [72, p. 18] "Dispersion (or specific surface area) is 
an independent thermodynamic parameter of the state of the system, a change in which causes corresponding changes in other equilibrium properties of the system. Dispersion acts as an intense feature of the system. This value can be compared with concentration, that is, with the amount of surface per unit volume. Thus, the surface acts as a separate component. In this case, you can draw an analogy with temperature or pressure. Preliminary consideration shows that dispersion is an independent and full-fledged thermodynamic parameter of the system. ... Thus, the surface tension is a partial derivative of any thermodynamic potential with respect to the interfacial area at constant corresponding parameters." This pattern was also demonstrated with specific examples in [73].

The destruction of water units by mechanical action does not raise questions. It turned out that low-intensity light also leads to the dissociation of the microdispersed phase of water. In fig. 7 shows the result of irradiating water with a $20 \mathrm{~mW}$ green LED laser for 10 minutes. Natural mineral drinking water "Serafimov Dar" was used in the experiment. Water was poured into a $100 \mathrm{ml}$ glass beaker; the light source was placed vertically directly above the water surface in the central zone equidistant from the glass walls. The microdispersed phase of water was examined under a microscope before and after irradiation (Figure 12).
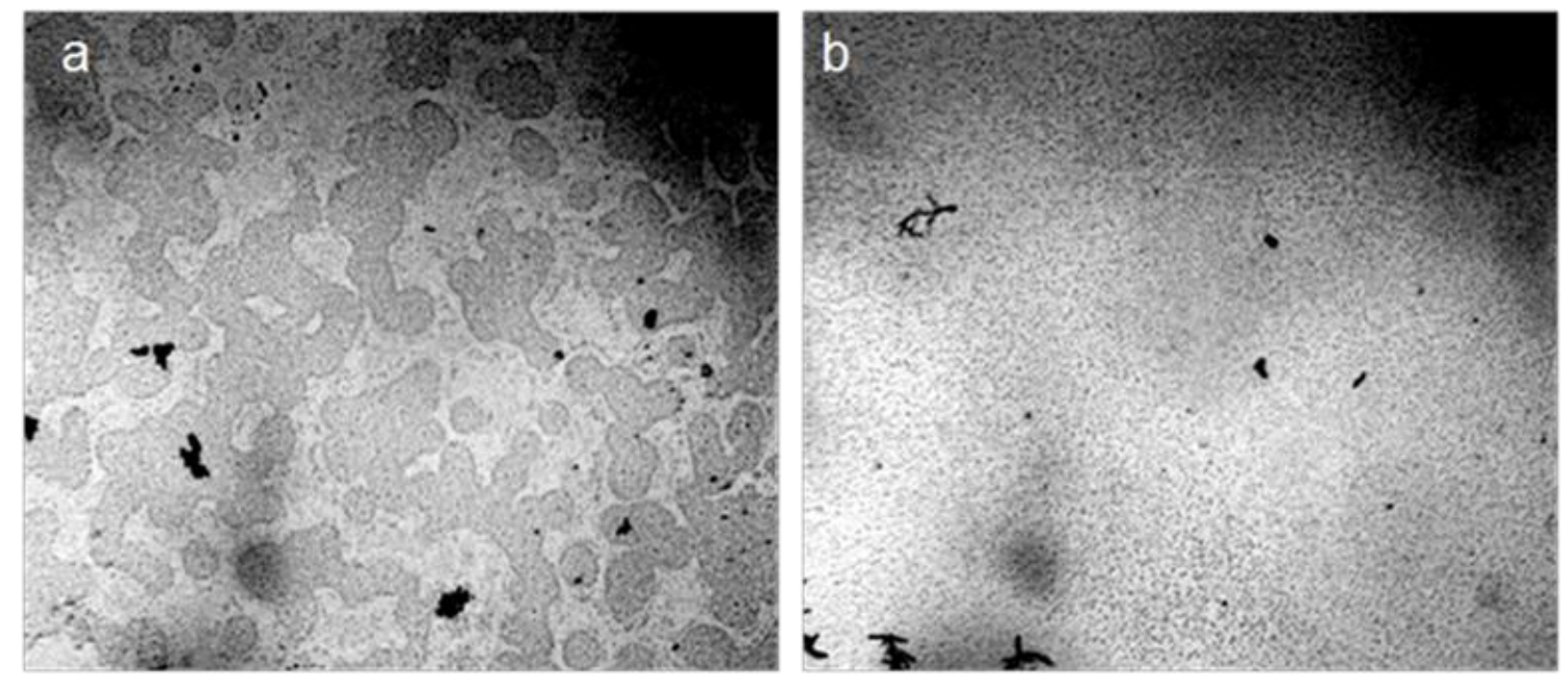

Figure 12. Microstructure of natural mineral drinking water "Serafimov Dar". Microscopy of a liquid layer $\sim 16 \mu \mathrm{m}$ thick before (a) and after (b) irradiation of a glass with water with a $20 \mathrm{~mW}$ green laser for 10 minutes.

It is obvious that irradiation led to the dissociation of large aggregates of the microdispersed phase. Simultaneously, there was also a decrease in the electrical capacity of the liquid by $\sim 1 \mathrm{pF}$ [74]. The changes were reversible and returned to baseline within an hour. A review of the available literature on the results of the impact on water of various disturbing factors of a physical nature made it possible to conclude that they all lead to the same consequences - an increase in $\mathrm{pH}$, a decrease in ORP, an increase in electrical conductivity, and a decrease in viscosity [73]. We associate these changes with the destruction of aggregates of the dispersed phase of water and an increase in the specific surface area of the system. 
The development of an original technique for obtaining samples of "solid-state water" by the method of repeated rinsing of hydrophilic surfaces in high-purity water and subsequent Iyophilization of the used liquid allowed the authors [75-82] to obtain solid-state microstructured sediment. The structure of the sediment depended on the nature of the hydrophilic substrate used (nafion, cellophane, cotton wool, filter paper). The physicochemical properties of water after repeated contact with different hydrophilic surfaces had a number of similar features: all samples contained associates $10^{-4} \mathrm{~m}$ in size, but in different concentrations, had a higher density and electrical conductivity than the initial water. According to the authors, the associates were a detached from the surface and crumpled EZ, as a result of mixing and deformation of the surfaces [81]. When water was disturbed by cellulose preparations, in particular, $\mathrm{pH}$, electrical conductivity, heat of mixing with acids or bases, and density changed. It is natural to assume that the nature of these changes is also associated with an increase in the specific surface area of the system caused by multiple mechanical disturbances.

In particular, this fact is confirmed by the linear correlation between electrical conductivity and other physicochemical variables [75]. In this case, the use of quantum electrodynamic field theory [84] to explain the observed changes seems to us excessive, since the determining events, as we see, develop not at the atomic, but at the micrometer level. Thus, the classical concepts of water as a liquid homogeneous at the micrometer level must be revised, since they do not correspond to reality.

Based on the features of the IR spectrum, the deconvolution of the $\mathrm{OH}$ stretching peak between 2880 and $3800 \mathrm{~cm}^{-1}$ shows the complete disappearance of the higher energy component by about $3600 \mathrm{~cm}^{-1}$ relative to bulk water [75]. This feature is characteristic of $\mathrm{OH}$ stretching in ice. It is also noted that "Other features appearing at $1418 \mathrm{~cm}^{-1}$ and $1105 \mathrm{~cm}^{-1}$, that are not present in liquid water, are difficult to attribute univocally at the present stage of knowledge." [74, p. 22]. Let us recall that the authors of the discovery of polywater faced a similar problem more than 50 years ago: "the complete absence of absorption from 2500 to $4000 \mathrm{~cm}^{-1}$, the presence of a strong band at about $1595 \mathrm{~cm}^{-1}$ and an intense doublet in the region of $1400^{-1}$ " [17] ... And further: "... we believe that water is restructured on the fused quartz or Pyrex surface into a polymeric form with bonds and bond energies completely different from that of ordinary water. Its properties are not those of water, and it should not be considered to be or even called water, any more than the properties of the polymer polyethylene can be directly correlated to the properties of the gas ethylene. In the case of the formation of polyethylene, a bond change occurs. In the case of polywater, a bond change also occurs, although it has previously been unknown. ... Vibrational spectra indicate unique stable polymeric structure "[17, p. 1486]. As you can see, the authors of the discovery of "polywater" also obtained it upon contact of ordinary water with hydrophilic surfaces - fused quartz and glass. Let us return to the publication by Lo et all [68]. The structures discovered by the authors - stable water clusters - at room temperature also had characteristic differences in the IR spectrum from ordinary water: the absorption peaks for pure water are $3283.5 \mathrm{~cm}^{-1}$ and $1634.5 \mathrm{~cm}^{-1}$. The absorption peaks for stable-water-clusters are $3371.4 \mathrm{~cm}^{-1}, 1639.5 \mathrm{~cm}^{-1}, 1342$ $\mathrm{cm}^{-1}, 822.5 \mathrm{~cm}^{-1}$. We see the same "red shift" and characteristic absorption for "water structures" obtained by other authors. The IR spectrometric analysis of the Nescafe Gold coffee 
solution ${ }^{1}$, in which we clearly observed aggregates of the dispersed phase of liquid crystalline water, revealed similar shifts [67]. To obtain the IR spectrum, a part of the sample dried to constant weight was ground in an agate mortar with a certain amount of $\mathrm{KBr}$ powder and pressed into a tablet. The IR spectrum was recorded on an IRRAFINITY-1 instrument (Shimadzu) in the range of wave numbers $400-4000 \mathrm{~cm}^{-1}$. The spectrum of a pure $\mathrm{KBr}$ tablet was used as a background. In Fig. 13 shows the IR spectrum of the sample at room temperature. It can be seen that, along with residues of free water $\left(3381.2 \mathrm{~cm}^{-1}\right)$, there are bands characteristic of structured water $\left(\sim 1600 \mathrm{~cm}^{-1}, \sim 1400 \mathrm{~cm}^{-1}, \sim 1100 \mathrm{~cm}^{-1}\right)$.

Thus, all the detected stable aqueous structures have similarities in the features of the IR spectrum characteristic of polywater. Does this mean that there are only two phases of water - continuous and near-wall (EZ), and the latter can also exist in the form of "water structures": EZ near hydrophilic impurities [60] or EZ, exfoliated from the substrate [64]. This second phase of water has a unified structure and corresponds to the previously described polywater [17].

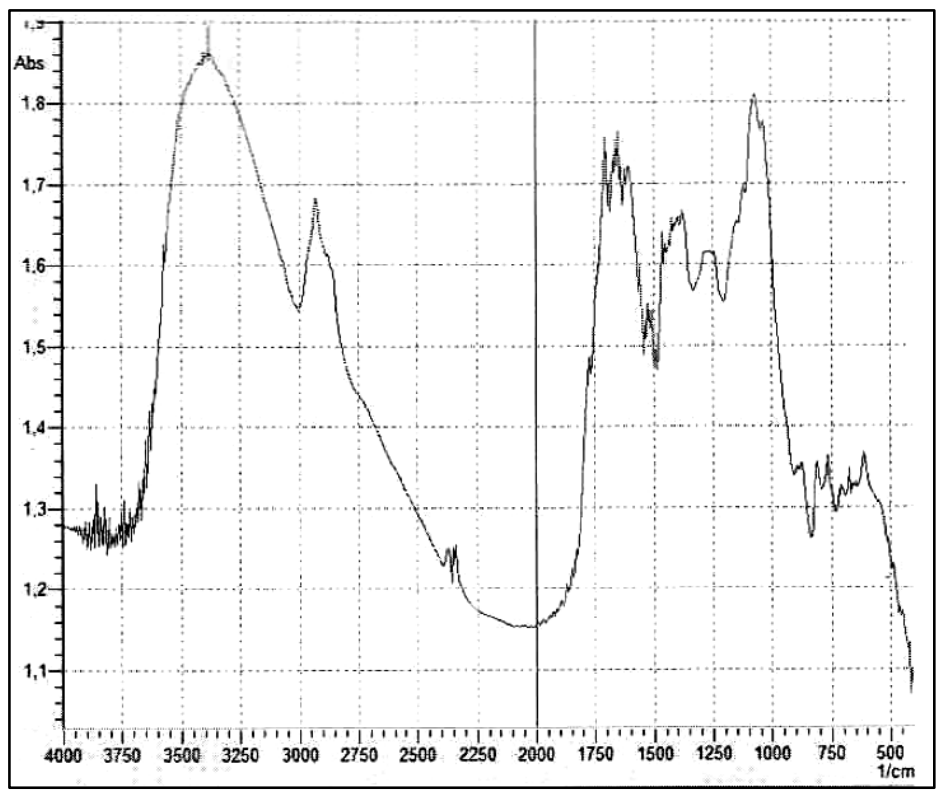

Figure 13. IR spectrum of dried powder of aqueous coffee solution at room temperature.

By the way, certain differences in the appearance of "dry water" obtained by iteration and lyophilization from different substrates (Nafion, cellophane, cotton wool, paper filter) can be explained by the presence of microparticles of these substrates in the sediments (see, for example, Fig. 2b [74 ]; Fig. 1-3 [78]; Fig. 6.7 [80]; Fig. 6.7 [81] All used substrates have a fibrous structure $[82,83]$, the micro-fragments of which can be torn off during repeated friction against water Since all the substrates used are hydrophilic, EZ is formed on their surface, which is revealed through the characteristic absorption in the IR spectrum.

This brief review is devoted to the discovery and development of only one idea about the interaction of water with hydrophilic surfaces and the existence of two phases of water at room temperature. These are continual water and structured water EZ, which is similar to

\footnotetext{
${ }^{1}$ The analysis was carried out in the laboratory of the N.I. Lobachevsky (head - Dr. V.F. Zanozina).
} 
polywater. This, in our opinion, is sufficient for a consistent explanation of all the phenomena described to date.

We have not touched upon the alternative opinion of a number of physicists - theorists on the structuring of water by the action of a "vacuum electromagnetic field" on it. According to Giuliano Preparata, Emilio Del Giudice and colleagues [87], liquid water is a two-fluid system, consisting of a coherent and incoherent phases. In the coherent phase, water molecules vibrate between two electronic configurations in phase with a resonating electromagnetic field (EMF) and, as a result, large stable coherent domains (CD) with a diameter of about $100 \mathrm{~nm}$ are formed in it at ordinary temperature and pressure. It is argued that these CDs can be responsible for all the special properties of water [68; 77; 84; 85], etc. Not all authors agreed with the adequacy of the presented model $[69 ; 83 ; 85]$. An attempt to combine two different views on the structure and dynamics of water was made in [87]. Undoubtedly, the involvement of quantum electromagnetic dynamics in the study of Nature is a promising theoretical tool, however, in the application to the problem considered here, we do not find a place for it.

Let us summarize what has been said.

Under room conditions, water is a microdispersed system with all its inherent properties. There are two phases of water: this is the usual continuous water and water, which is a cyclic polymer $\mathrm{H}_{2} \mathrm{O}$, consisting of flat layers of hexagonal cells superimposed on each other (polywater). Polywater can exist as a near wall layer at hydrophilic surfaces (EZ), and as "micron-sized structures" floating in continual water. The structures are prone to the formation of aggregates (coagulates) tens and hundreds of microns in size. The degree of water dispersion determines its physicochemical properties. The downsizing of aggregates by any disturbance leads to a decrease in viscosity, an increase in electrical conductivity, an increase in $\mathrm{pH}$, and a decrease in ORP. That is, the reason for the change in properties lies at the micrometer level, accessible for observation under an ordinary light microscope, and this reason is a change in the "surface concentration". We consider the continuation of research in this area to be promising.

In conclusion, let us remember the statement of A. Schweitzer: "Any truth is first ridiculed and then recognized."

Funding: This project was funded by the Ministry of Education and Science of Russia (project No 14.Y26.31.0022).

Conflicts of Interest: The authors declare no conflict of interest.

\section{References}

1. Eisenberg, D. and Kauzmann, W. The structure and properties of water. Oxford University Press, 1997, 318 p. ISBN-10 : 0198570260.

2. Pang, X- F. Water: molecular structure and properties. Word Scientific Publishing Co. Pte. Ltd. 2014, 492 p. ISBNN 978-9814440424. 
3. Henniker, J. C. The depth of surface zone of a liquid. Reviews of modern physics, 1949, 21(2), $322-$ 341.

4. Macey, H. H. Clay-water relationships and the internal mechanism of drying. Trans. Brit. Ceram. Soc., 1942, 41, 73-121.

5. Kolkmeijer, N. H. and Favejee, J. C. L. The Structure of Emulsoid Sol Particles and their Hydration Film. Nature, 1933, 133, 602.

6. Mering, J. On the hydration of montmorillonite. Trans. Faraday Soc., 1946, 42B, 205-224.

7. Williamson, W.O. The clay/water relation. ReSearch, London, 1948, 1, 363-371.

8. Derjaguin, B. Die Formelastizität der dünnen Wasserschichten. Zeitschrift für Physik, 1933, 84, 657670. https://doi.org/10.1007/BF01330408

9. Deryagin, B.V. Range of Action of Surface Forces. Nature, 1936, 138, 330-331.

10. Terzaghi, C.; Angew, Z. Math. Mech. 1924 4, 10'7. (As quoted in Hennicker's review [3]).

11. Norton, H. and Johnson, A. L. Fundamental study of clay: $v$, nature of water film in plastic clay. J. Am. Cer. Soc., 1944, 21, 77-80. https://doi.org/10.1111/j.1151-2916.1944.tb14872.x

12. Derjagin, B.V.; Churaev, N.V.; Fedyakin, N.N.; Talaev, M.V.; Ershova, I.G. Modified state of water and other liquids. Izvestiya Akademii Nauk SSSR, seriya khimicheskaya, 1967, 10, 2178. (In Russian)

13. Ice-nine, Russian style, in the book: S. J. Gould. The Mismeasure of Man. Norton, 1996, 447 pp. Available online: http://www.nytimes.com/1981/08/30/books/ice-nine-russianstyle.html?pagewanted=all (accessed on 11 August 2000).

14. Franks F. Polywater. Cambridge, MA: The MIT Press, 1982, 208 pp.

15. Derjagin, B.V. New data on superdense water. Uspekhi fizicheskikh nauk, 1970, 100(4), 726-728.

16. Derjagin, B. Abnormal water - hypotheses and facts.11.03.2007. (In Russian). Available online: www.o8ode.ru/article/water/udivit/anomalwater.htm (accessed on 7 May 2008).

17. Lippincott, E.R.; Stromberg, R.R.; Grant, W.H.; Cessac, G.L. Polywater. Science, 1969, 164, 14821487.

18. Rousseau, D.L.; Porto, S.P.S. Polywater: polymer or artifact? Science, 1970, 167, 1715-1719.

19. Davis, R.E.; Rousseau, D.L.; Board, R.D. "Polywater:" Evidence from electron spectroscopy for chemical analysis (ESCA) of a complex salt mixture. Science, 1971, 171, 167-170.

20. Kurtin, S.L.; Mead, C.A.; Mueller, W.A.; Kurtin, B.C.; Wolf, E.D. "Polywater": a hydrosol? Science, 1970, 167, $1720-1722$.

21. Rousseau, D.L. "Polywater" and sweat: similarities between the infrared spectra. Science, 1971, 171, 170-172.

22. Ginzburg, V.L. What problems of physics and astrophysics seem to be especially important and interesting? Uspehi fizicheskih nauk, 1971, 103, 87, 93-94. (In Russian).

23. Derjaguin, B. V.; Churaev, N. V. Nature of “Anomalous Water". Nature, 1973, 244, 430-431.

24. Derjagin, B.V.; Sorin, Z.V.; Rabinovich, Ya. I.; Churaev, N.V. Rezults of analytical investigation of the composition of "anomalous" water. Journal of colloid and Interface science, 1974, 46(3), 437-441.

25. Derjagin, B.V. The world of colloid-superficial phenomena. Vestnik Akademii Nauk SSSR. The heading "From the notebook of the researcher" 1990, 9, 68-75. (In Russian).

26. Pershin, S.M. Two-liquid water. Physics of Wave Phenomena, 2005, 13(4), 192-208.

27. Huang, C.; Wikfeldt, K. T.; Tokushima, T.; Nordlund, D.; Harada, Y.; Bergmann, U.; Niebuhr, M.; Weiss, T. M.; Horikawa, Y.; Leetma, M.; Ljungberg, M. P.; Takahashi, O.; Lenz, A.; Ojama, L.; Lyubartsev, A. P.; Shin, S.; Pettersson, L. G. M. and Nilsson, A. The inhomogeneous structure of water at ambient conditions. Proc. Nat. Acad. Sci. USA, 2009, 106, 15214-15218

28. Maestro, L.M.; Marqués, M.I.; Camarillo, E.; Jaque, D.; García Solé, J.; Gonzalo, J.A.; Jaque, F.; del Valle, J.C.; Mallamace, F.; Stanley, H.E. Int. J. Nanotechnol. 2016, 13(8/9), 667-677. 
29. Gallo, P.; Amann-Winkel, K.; Angell, C. A.; Anisimov, M. A.; Caupin, F.; Chakravarty, C.; Loerting, T.; Panagiotopoulos, A. Z.; Russo, J.; Tanaka, H., Vega, C.; Xu,L. and Pettersson, L. G.M. Water: A tale of two liquids. Chem. Rev., 2016, 116, 7463-7500. https://doi.org/10.1021/acs.chemrev.5b00750

30. Russo, J. and Tanaka, H. Understanding water's anomalies with locally favoured structures. Nature Communications, 2014, DOI: 10.1038/ncomms4556.

31. Renati, P.; De Ninno, Z. A. and Tsenkova, R. Temperature Dependence Analysis of the NIR Spectra of Liquid Water confirms the existence of two phases, one of which is in a coherent state. Journal of Molecular Liquids, 2019, 292, 111449.

https://www.sciencedirect.com/science/article/abs/pii/S0167732219331617

32. Preparata, G; Messina, B; Talpo, G.; Gigante, G.E.; Del Giudice, E.; Bizzarri, M.; Sermonti, G.; Grieco, U.; Valenzi, V.; Roseghini, M.L. The Role of QED (Quantum Electro Dynamics) in Medicine. Proceedings of Meeting 14/12/1999 Institute of Pharmacology University of Rome "La Sapienza" 2000, 1-27. http://www.22passi.it/downloads/biorisonanza/qeddefinitivo.pdf

33. Hu, J.; Xiao, X.-d.; Ogletree, D.F.; Salmeron M. The structure of molecularly thin films of water on mica in humid environments. Surface Science, 1995, 344(3), 221-236 https://doi.org/10.1016/0039$\underline{6028(95) 00858-6}$

34. Aarts, I. M. P.; Pipino, A. C. R.; Hoefnagels, J. P. M.; Kessels, W. M. M. and van de Sanden, M. C. M. Quasi-Ice Monolayer on Atomically Smooth Amorphous $\mathrm{SiO}_{2}$ at Room Temperature Observed with a High-Finesse Optical Resonator. Physical Review Letters, 2005, 95(16), 166104. DOI: 10.1103/PhysRevLett.95.166104

35. Jinesh, K. B. and Frenken, J.W. M. Capillary Condensation in Atomic Scale Friction: How Water Acts like a Glue. Physical review letters, 2006, 96, 166103.

36. Jinesh, K. B. and J. Frenken, W. M. Experimental Evidence for Ice Formation at Room Temperature Physical review letters, 2008, 101, 036101.

37. Striolo, A. From interfacial water to macroscopic observables: a review. Adsorption Science \& Technology, 2011, 29(3), 211-258.

38. Sendner, C.; Horinek, D.; Bocquet, L. and Netz, R.R. Interfacial Water at Hydrophobic and Hydrophilic Surfaces: Slip, Viscosity, and Diffusion. Langmuir, 2009, 25, 10768-10781.

https://doi.org/10.1021/la901314b

https://www.academia.edu/16943925/Interfacial Water at Hydrophobic and Hydrophilic Surfac es Slip Viscosity and Diffusion

39. Pollack, G. The fourth phase of water: beyond solid, liquid, and vapor. Ebner and Sons Publishers, 2013, $320 \mathrm{p}$.

40. Zheng, J.; Chin, W-C; Khijniak, E.; Khijniak, E. Jr.; Pollack, G. Surfaces and interfacial water: evidence that hidrophylic surfaces have long-range impact. ACIS, 2006, 127, 19-27.

41. Yakhno, T.A.; Yakhno, V.G. Water-induced self-oscillatory processes in colloidal systems by the example of instant coffee. Journal of Basic and Applied Research International, 2017, 20(2), 70-83.

42. Fenter, P.; Sturchio, N.C. Mineral-water interfacial structures revealed by synchrotron X-ray scattering. Prog. Surf. Sci., 2004, 77, 171-258.

43. Verdaguer, A.; Sacha, G.M.; Bluhm, H.; Salmeron, M. Molecular Structure of Water at Interfaces: Wetting at the Nanometer Scale. Chem. Rev., 2006, 106, 1478-1510.

44. Maccarini, M. Water at solid surfaces: A review of selected theoretical aspects and experiments on the subject. Biointerphases, 2007, 2, MR1-MR15.

45. Maurya, M.; Metya, A.K.; Singh, J.K., and Saito, S. Effects of interfaces on structure and dynamics of water droplets on a graphene surface: a molecular dynamics study. J. Chem. Phys., 2021, 154, 164704. doi: 10.1063/5.0046817 
46. Del Giudice, E.; Tedeschi, A.; Vitiello, G. and Voeikov, V. Coherent Structures in Liquid Water Close to Hydrophilic Surfaces. Journal of Physics: Conference Series, 2013, 442, Article ID: 012028. https://doi.org/10.1088/1742-6596/442/1/012028 https://iopscience.iop.org/article/10.1088/1742-6596/442/1/012028/pdf

47. Schurr, J.M. Phenomena Associated with Gel-Water Interfaces. Analyses and Alternatives to the Long-Range OrderedWater Hypothesis. J. Phys. Chem. B, 2013, 117, 7653-7674.

48. Elton, D.C.; Spencer, P.D.; Riches, J.D.; Williams, E.D. Exclusion Zone Phenomena in Water-A Critical Review of Experimental Findings and Theories. Int. J. Mol. Sci. 2020, 21, 5041. doi:10.3390/ijms21145041.

49. Esplandiu, M.J.; Reguera, D. and Fraxedas, J. Electrophoretic origin of long-range repulsion of colloids near water/Nafion interfaces. Soft Matter, 2020,16, 3717-3726.

50. Huszár, I.; Mártonfalvi, Z.; Laki, A.; Iván, K.; Kellermayer, M. Exclusion-Zone Dynamics Explored with Microfluidics and Optical Tweezers. Entropy 2014, 16, 4322-4337.

51. Ninham, D.W.; Bolotskova, P.N.; Gudkov, S.V.; Juraev, Y.; Kiryanova, M.S.; Kozlov, V.A.; Safronenkov, R.S.; Shkirin, A.V.; Uspenskaya, E.V. and Bunkin, N.F. Formation of Water-Free Cavity in the Process of Nafion Swelling in a Cell of Limited Volume; Effect of Polymer Fibers Unwinding. Polymers 2020, 12, 2888; doi:10.3390/polym12122888 www.mdpi.com/journal/polymers

52. Pollack, G.H. Comment on "A Theory of Macromolecular Chemotaxis" and "Phenomena Associated with Gel-Water Interfaces. Analyses and Alternatives to the Long-Range Ordered Water Hypothesis". J. Phys.Chem. B, 2013, 117, 7843-7846.

53. A.N. Smirnov, A.V. Syroeshkin. Supratmolecular water complexes. // Ros. Chem. J., 2004, XLVIII (2), 125-135 (In Russ.).

54. Smirnov, A.N.; Lapshin, V.B.; Balshev, A.V.; Lebedev, I.M.; Goncharuk, V.V.; Syroeshkin, A.V. Water Structure: Giant Heterophase Water Clusters. Chemistry and Water Technology, 2005, 27(2), 111136 (In Russian).

55. Bunkin, N.F.; Suyazov, N. V.; Tzipenyuk, D.Yu. Laser radiation small emulsion scattering on the stable formations of a micron scale in twice distilled water. Quantum electronics, 2005, 35(2). 180184 (In Russian).

56. Sedlak, M.J. Large-scale supramolecular structure in solutions of low molar mass compounds and mixtures of liquids: I. Light scattering characterization. J. Phys. Chem. B, 2006, 110 (9) 4329-4338.

57. Smirnov, A.N. Outmolecular water complexes: emulsions. Living Physics, 2010, 18 (2), 23-33 (In Russian).

58. Bukatyi, V.I.; Nesteryuk, P.I. The study of optical inhomogeneities (clusters) in bidistillated water with an optical method of small angles. Polzunovsky Vestnik, 2011, 3(1), 106-108. (In Russian).

59. Yakhno, T.A.; Yakhno, V.G. Microstructure and phase transitions of water according to optical microscopy. Proceedings of the second all-Russian conference "Physics of aqueous solutions", October 17-18, 2019, Moscow, 2019, 44-45. (in Russian)

https://www.researchgate.net/publication/336678616 Mikrostruktura i fazovye perehody vody po dannym opticeskoj mikroskopii

60. Yakhno, T., Yakhno, V. A study of structural organization of water and aqueous solutions by means of optical microscopy. Crystals, 2019, vol. 9, no 1, p. 52. DOI:10.3390/cryst9010052. http://www.mdpi.com/2073-4352/9/1/52

61. Yakhno, T.A.; Yakhno, V.G. Study of the role of microdispersed phase of water during its transition to activated state. Russian journal of biological physics and chemistry, 2020, 5(1), 43-51 (In Russian). 
62. Yakhno, T.; Drozdov, M.; Yakhno, V. Giant Water Clusters: Where Are They From? Int. J. Mol. Sci. 2019, 20, 1582; doi:10.3390/ijms20071582. https://www.mdpi.com/1422-0067/20/7/1582

63. Yakhno, T.A.; Yakhno, V.G. Physical - chemical evolution of the dispersed phase of water when it dryes. Russian journal of biological physics and chemistry, 2019, 4(1), 9-16 (In Russian).

64. Zhang, Y.; Takizawa, S., and Lohwacharin, J. Spontaneous Particle Separation and Salt Rejection by Hydrophilic Membranes. J. WATER, 2015, 7, 1-18. doi: 10.14294/WATER.2015.2.

65. Zheng, J.M.; Chin, W.C.; Khijniak, E., Khijniak Jr, E.; Pollack, G.H. Surfaces and Interfacial Water: Evidence that Hydrophilic Surfaces Have Long-Range Impact. Adv. Colloid Interface Sci., 2006 ,127, 19-27.

66. Zheng, J.M. and Pollack, G.H. Long-Range Forces Extending from Polymer-Gel Surfaces. Phys. Rev. E, 2003, 68, 031408.

67. Yakhno, T.A.; Yakhno, V.G.; Zanozina, V.F. Phase transitions of water as a source of slow oscillatory processes in liquid media. In Proceedings of the XII International Science-Technical Conference "Modern Trends in Biological Physics and Chemisitry", Sevastopol, Russia, 2-6 October 2017; $23-27$. (In Russian).

68. Lo, S.Y.; Geng, X.; Gann, D. Evidence for the existence of stable-water-clusters at room temperature and normal pressure. Physics Letters A, 2009, 373, p. 3872-3876.

doi:10.1016/j.physleta.2009.08.061.

69. Ho M-W. Large Supramolecular Water Clusters Caught on Camera - A Review. Water, 2013 doi: 10.14294/WATER.2013.12

70. James R.; Seddon T.; Lohse D. Nanobubbles and micropancakes: gaseous domains on immersed substrates. J. Phys.: Condens. Matter, 2011, 23, 133001.

doi:10.1088/0953-8984/23/13/133001 Online at stacks.iop.org/JPhysCM/23/133001

71. Zhang L.; Zhang X.; Fan C.; Zhang Y. and Hu J. Nanoscale multiple gaseous layers on a hydrophobic surface. Langmuir, 2009, 25(16), 8860-4. doi: 10.1021/la901620e.

72. Borilo, L.P. Thin-film inorganic nanosystems (ed. prof. V.V. Kozik). - Tomsk: Tomsk State University, 2012, 134 p. ISBN 978-5-94621-362-2 (In Russian.).

73. Yakhno, T.A.; Yakhno, V.G. Study of the role of the microdispersed phase of water during its transition to the state of activation. Russian journal of biological physics and chemistry, 2020, 5(1), 43-51. (In Russian).

74. Elia, V.; Ausanio, G.; De Ninno, A.; Gentile, F.; Germano, R.; Napoli, E.; Niccoli, M. Experimental evidence of stable aggregates of water at room temperature and normal pressure after iterative contact with a Nafion ${ }^{\circledR}$ polymer membrane. Water, 2013, 5, 16-26. doi: 10.14294/WATER.2013.4.

75. Elia, V.; Napoli, E,; Niccoli, M. Physical-chemical study of water in contact with a hydrophilic polymer: Nafion. J Therm Anal Calorim. 2013, 112, 937-44.

76. Elia, V.; Lista, L.; Napoli, E.; Niccoli, M. A thermodynamic characterization of aqueous nanostructures of water molecules formed by prolonged contact with the hydrophilic polymer Nafion. J Therm Anal Calorim. 2014, 115,1841-9.

77. Elia, V.; Germano, R.; Napoli E. Permanent dissipative structures in water: the matrix of life? Experimental evidences and their quantum origin. Curr Top Med Chem. 2015, 15, 559-71.

78. Elia, V.; Yinnon, T.A.; Oliva, R.; Napoli, E.; Germano, R.; Bobba, F.; Amoresano, A. Chiral micron-sized $\mathrm{H} 2 \mathrm{O}$ aggregates in water: circular dichroism of supramolecular $\mathrm{H} 2 \mathrm{O}$ architectures created by perturbing pure water. Water, 2017, 8:1-29.

79. Yinnon, T.A.; Elia, V.; Napoli, E.; Germano, R.; Liu, Z-Q. Water ordering induced by interfaces: an experimental and theoretical study. Water. 2016, 7:96-128. 
80. Elia, V.; Napoli, E.; Germano, R.; Roviello, V.; Oliva, R.; Niccoli, V.; Amoresano, A.; Toscanesi, M.; Trifuoggi, M.; Fabozzi, A.; Yinnon, T.A. Water perturbed by cellophane: comparison of its physicochemical properties with those of water perturbed with cotton wool or Nafion. Journal of Thermal Analysis and Calorimetry, 2020. https://doi.org/10.1007/s10973-020-10185-0

81. Elia, V.; Napoli, E.; Germano, R.; Oliva, R.; Roviello, V.; Niccoli, M.; Amoresano, A.; Naviglio, D.; Ciaravolo, M.; Trifuoggi, M.; Yinnon, T.A. New chemical-physical properties of water after iterative procedure using hydrophilic polymers: The case of paper filter. Journal of Molecular Liquids, 2019, 296, 111808. https://doi.org/10.1016/j.molliq.2019.111808

82. Loelovich, M. Ya. Models of supermolecular structure and properties of cellulose. High-molecular compounds, Ser. A, 2016, 58(6), 604-624. (In Russian).

83. Gallyamov, M.O.; Khokhlov, A.R. Polymer Membrane Fuel Cells: Materials for the Fuel Cell Fundamentals course. Moscow: Faculty of Physics, Moscow State University, 2014, 72 p. ISBN 9785-600-00346-0 (In Russian).

84. Del Giudice, E.; Preparata, G.; Vitiello, G. Water as a Free Electric Dipole Laser. Physical Review Letters, 1988, 61(9), 1085-1088.

85. Yinnon, T.; Liu, Z-Q. Domains Formation Mediated by Electromagnetic Fields in Very Dilute Aqueous Solutions: 1. Quantum Electrodynamic Aspects. Water, 2015, 7, 33-47. doi: 10.14294/WATER.2015.4.

86. Bier, M.; Pravica, D. Limits on quantum coherent domains in liquid water. Acta Physica Polonica B, 2018, 49(9), 1717-1731. DOI:10.5506/APhysPolB.49.

87. Messori, C. Deep into the Water: Exploring the Hydro-Electromagnetic and QuantumElectrodynamic Properties of Interfacial Water in Living Systems. Open Access Library Journal, 2019, 6, e5435. https://doi.org/10.4236/oalib.1105435 